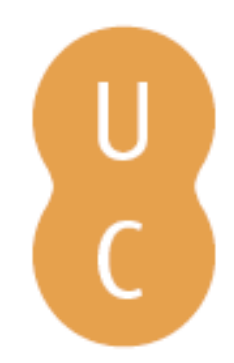

\title{
pompalina
}

\section{Relatos de experiência em Paulo Freire no curso de Pedagogia da Unifimes}

Autor(es): $\quad$ Pereira, Luciene Aparecida Pinto Costa; Pereira, Marcos Vinicius Costa

Publicado por: Imprensa da Universidade de Coimbra

URL

persistente: URI:http://hdl.handle.net/10316.2/41311

DOI: $\quad$ DOI:https://doi.org/10.14195/978 98926 1326-0_22

Accessed : $\quad$ 26-Apr-2023 07:40:31

A navegação consulta e descarregamento dos títulos inseridos nas Bibliotecas Digitais UC Digitalis, UC Pombalina e UC Impactum, pressupõem a aceitação plena e sem reservas dos Termos e Condições de Uso destas Bibliotecas Digitais, disponíveis em https://digitalis.uc.pt/pt-pt/termos.

Conforme exposto nos referidos Termos e Condições de Uso, o descarregamento de títulos de acesso restrito requer uma licença válida de autorização devendo o utilizador aceder ao(s) documento(s) a partir de um endereço de IP da instituição detentora da supramencionada licença.

Ao utilizador é apenas permitido o descarregamento para uso pessoal, pelo que o emprego do(s) título(s) descarregado(s) para outro fim, designadamente comercial, carece de autorização do respetivo autor ou editor da obra.

Na medida em que todas as obras da UC Digitalis se encontram protegidas pelo Código do Direito de Autor e Direitos Conexos e demais legislação aplicável, toda a cópia, parcial ou total, deste documento, nos casos em que é legalmente admitida, deverá conter ou fazer-se acompanhar por este aviso. 


\title{
22. RELATOS DE EXPERIENCIA EM PAULO \\ FREIRE NO CURSO DE PEDAGOGIA DA \\ U N I F I M E S
}

\author{
Luciene Aparecida Pinto Costa Pereira ${ }^{116}$ \\ Marcos Vinicius Costa Pereira 117
}

\section{Resumo}

Este relato de Experiências Acadêmicas na Concepção Freireana, é resultado do trabalho desenvolvido no Curso de Pedagogia da Unifimes da cidade de Mineiros-GO (Brasil), desde 2013 nas disciplinas de Estágio Supervisionado I, II e II e na disciplina de Psicomotricidade, Brincadeiras e Jogos na Educação. O trabalho teve como objetivo superar o paradigma conservador e os preceitos neoliberais que os graduandos vêm enfrentando na sua formação acadêmica. Propusemos trabalhar as obras de Freire: Pedagogia do Oprimido (1987), Pedagogia da Autonomia (1996), A educação na cidade (2000), Pedagogia da esperança: um reencontro com Pedagogia do oprimido (1992), Professora

116 Mestre em Educação pela Universidade Federal de Goiás e graduada em História pela Faculdade de Ciências e Letras de Catanduva -SP e atua como professora do Curso de Pedagogia na Unifimes e é coordenadora pedagógica do Colégio Estadual Deputado José Alves de Mineiros-GO.

117 Graduando em Engenharia Civil pela Pontifícia Universidade Católica de Goiás - PUC-Goiás. 
sim, tia não: cartas a quem ousa ensinar (1995), A importância do ato de ler (1982) e Pedagogia da indignação (2000). O trabalho em sala de aula com os estagiários e em campo com os coordenadores, gestores e educadores nas Creches Filantrópicas e nas escolas da Rede Municipal de Ensino da cidade de Mineiros-GO, nos quais foram trabalhadas Formação Continuada, Rua do Lazer - Tarde da Pipa e aulas de regências, teve como orientação teórica o materialismo-histórico-dialético, porque compreendemos que para entender as obras de Paulo Freire esta orientação vem ao encontro da própria postura que o autor assumiu quando utilizou o conceito de classe, abandonando o conceito de nação.

\section{Abstract}

This report of Academic Experiences under Freire's Conceptions is the result of activities developed in the Pedagogy course of Unifimes from Mineiros-GO (Brazil), particularly in the discipline of Supervised Practice I, II and III and the discipline of Psychomotricity, Play and Games in Education. This study aimed to overcome the conservative paradigm and the neoliberal precepts that students are facing today in their academic training. We proposed the reading of works of Freire: Pedagogy of the Oppressed (1987), Pedagogy of Autonomy (1996), Pedagogy of the City (2000), Pedagogy of Hope: Reliving the Pedagogy of the Oppressed (1992), Teachers as Cultural Workers: Letters to who dare teach (1995), The Importance of the Act of Reading (1982), and Pedagogy of Indignation (2000). The work was developed in classes with the future teachers and in the field with coordinators, managers and educators, in Philanthropic Kindergartens and schools from the Municipality of Mineiros-GO. The activities included inservice training of teachers, 
"Rua do Lazer - Tarde da Pipa" and practical classes and were theoretically oriented by the historical-dialectical-materialism - because we believe that, to understand Paulo Freire's works, this is the appropriate approach, once this orientation meets the position that the author took when used the concept of class, abandoning the concept of nation. 


\section{Introdução}

Para Freire (1997)

[...] ensinar não é transferir a inteligência do objeto ao educando, mas instigá-lo no sentido de que, como sujeito cognoscente, se torne capaz de inteligir e comunicar o inteligido. É nesse sentido que se impõe a mim escutar o educando em suas dúvidas, em seus receios, em sua incompetência provisória. E ao escutá-lo, aprendo a falar com ele. (p.135)

Trabalhar com a formação de professores tem sido um grande desafio no Brasil, porque o discurso neoliberal tem orientado as políticas educacionais, trazendo em seu bojo uma concepção de que a educação precisa ser útil às demandas imediatas do mercado e, com isso, palavras de ordem como: qualidade total, adequação do ensino à competitividade do mercado internacional, produtividade, pesquisas práticas, financiamentos empresariais e flexibilidade, têm permeado toda esta política. O que representam estas palavras dentro do contexto da formação de professores?

Lembremos a história de Idries Shah:

Certo dia Nasrudin encontrou um falcão sentado no parapeito da janela. Ele nunca havia visto um pássaro desta espécie em sua vida. "Pobre criatura!", exclamou compadecido. "Como puderam te deixar chegar a este estado! "Cortou as garras do falcão, aparou o seu bico, e podou as suas penas. "Agora”, exclamou Nasrudin satisfeito, "agora você está com mais cara de pássaro." (Shah, 1999, p. 220).

A história supracitada representa os cortes, os interesses do capital, no qual a educação deixa de ser um direito e se torna uma mercadoria, escrava dos princípios mercadológicos, reduzindo sua função apenas 
aos interesses econômicos. Neste sentido, a formação de professores acaba cedendo a estas pressões de uma formação rápida, aligeirada e domesticada, como o falcão sentado no parapeito da janela, no qual sua identidade deve ser construída segundo os interesses do capital.

O surgimento deste novo profissional da educação atrelado aos interesses do capital, emerge na década de 1970 e 1980, sob a influência da Unesco e da Unicef e, a partir de 1990 o Banco Mundial passa a regulamentar a política educacional, junto ao Fundo Monetário Internacional (FMI), uma espécie de "caixa" para os países que necessitem de injeção de capital em suas economias.

Afinal, qual é a função que o Banco Mundial ou Bird (Banco Internacional para a Reconstrução e o Desenvolvimento) exerce?

Tal banco foi criado na Conferência Bretton Woods em 1944, durante a Segunda Guerra Mundial (1939-1945), para estruturar países que tiveram suas economias arrasadas no período da guerra. À medida em que os países europeus começaram a se recuperar economicamente, o Banco passou a ajudar países do sul em processo de descolonização, sem que os mesmos conseguissem superar os fatores que os levaram ao empobrecimento.

Segundo Arruda (1998: 47)

Doze por cento dos empréstimos do Banco (US $\$ 2,4$ bilhões) vão para processos de reformas econômicas e institucionais (ajuste), que pretendem estabelecer as bases para o crescimento econômico. Contudo, a maioria dos programas de ajuste são vistos como tendo consequências perversas para a grande parte da população e para o meio ambiente, solapando a segurança alimentar dos países tomadores e acentuado a concentração da renda e do acesso aos recursos produtivos.

Esta é a dinâmica do BM, considerado uma espécie de Agência de Crédito cuja finalidade é fornecer empréstimos a países de 
Terceiro Mundo, desde que os mesmos respeitem, claro, todas as normativas do banco.

O BM empresta dinheiro aos países pobres com juros altíssimos, com a finalidade de alívio à pobreza, de tal forma que esta parcela da população se sinta inserida no processo, não se volte contra as políticas governamentais e não tenda a se interessar por sistemas econômicos voltados para o comunismo.

Vale ressaltar que até 1960 a educação e a saúde não eram prioridades do Banco. Esta situação começou a mudar a partir da década de 1970, na gestão de Robert S. MacNamara (1968-1981), que considerou ser de suma importância este organismo atuar nestas áreas (Leher, 1998, p. 202). Com isso, a educação passa a ser regida por uma lógica econômica, na qual a escola deve estar a serviço dos novos cânones da globalização.

À vista disso, a educação é considerada pelo BM um "mal necessário", no qual a figura do professor é secundária e a própria pedagogia deixa de ser o centro do processo educativo. Em seu lugar as tecnologias e a educação à distância passam a ser o centro de todo processo de aprendizagem, tendo como consequência o barateamento da formação do docente.

O professor passa a ser valorizado mais pelas suas experiências, porque estas sim, podem resolver os problemas do cotidiano, podem dar ao professor o know-how, as "competências" necessárias para solucionar os problemas.

Como resultado desta política do $\mathrm{BM}$, temos uma educação voltada para o pragmatismo, que reduz todo o sentido do conhecimento a um racionalismo utilitarista, uma educação pobre para um povo pobre, que não precise pensar, apenas executar os comandos das políticas neoliberais.

Foi tentando romper com toda essa lógica da produção que o curso de pedagogia da Unifimes buscou em Paulo Freire a concepção de educação para nortear o PPC do curso, incluindo 
obras do referido autor nas disciplinas que compõem a matriz curricular.

A inclusão das obras freireanas na formação de professores corroborou com os objetivos das disciplinas de Estágio Supervisionado I, II e III e Psicomotricidade, Brincadeiras e Jogos na Educação, que consistem em superar o paradigma conservador e os preceitos neoliberais, nos quais o conhecimento se torna fragmentado e respaldado na ação-reflexão-ação, uma educação a que Paulo Freire (1975) descreve como educação "bancária".

Para o autor "ensinar não é simples transmissão de conhecimento em torno do objeto ou do conteúdo" (1992, p. 81), é ir muito mais além, porque conhecimento se adquire numa ação dialógica, na qual as relações de trabalho são estabelecidas como um ato político através do qual se dá a mudança social. Não existe processo educativo se não tiver uma consciência crítica, uma reflexão da sua práxis.

Para melhor compreender a questão da práxis a que Paulo Freire se refere, é importante nos remeter ao percurso teórico que o autor fez, ao analisar a consciência comum da práxis, tema este recorrente na obra Filosofia da Práxis de Adolfo Sánchez Vazquez (1977).

Segundo Vazquez (1977, p. 5)

[...]a práxis é a categoria central da filosofia que se concebe ela mesma não só como interpretação do mundo, mas também como guia de transformação. Tal filosofia não é outra senão o marxismo. Mas essa consciência filosófica da práxis não deixa de ter antecedentes no passado nem tampouco surge sob forma acabada com a filosofia de Marx. O certo é que depois de superar o nível atingido pelo idealismo alemão, o marxismo representa [...] sua a consciência mais elevada, bem como a vinculação mais profunda com a práxis real. 
A concepção marxista da práxis para o autor não é uma volta pré-filosófica e nem a filosofia da práxis do idealismo hegeliano, e sim um avanço no sentido dialético de negar e absorver ambos. Para Vazquez (1977, p. 6) a práxis idealista é "[...] uma filosofia da práxis, embora a atividade prática humana nele se apresente de modo abstrato e mistificado".

$O$ autor acredita que não se supera essa concepção idealista, utilizando o "senso comum", mas sim com outra teoria da filosofia que, [...] por seu caráter materialista, científico, eleva-se ainda mais do que o idealismo sobre a consciência comum" (p. 6), ou seja, a práxis é uma atividade material do homem social.

Só que este homem tem que se reconhecer como um ser-histórico, para conseguir romper, transcender os limites da consciência comum, superar o ponto de vista espontâneo ou instintivo.

Para romper com tudo isso, Freire (1979) propõe que na educação há possibilidade de uma reflexão e ação perante a realidade em que estamos inseridos, porque a práxis está ligada ao ato pedagógico que é a teoria e a prática, e esta relação é marcada pela dialogicidade, através da qual é possível combater a ignorância, buscar a sabedoria, se reconhecer oprimido e opressor, tanto o educando quanto o educador; e, além disso, perceber que nossa consciência precisa vencer as etapas da consciência mágica, ingênua, fanatizada para chegar a consciência crítica deixando o pragmatismo e o senso comum de lado.

Por isso, Alessandra Arce (2001, p. 267) não acredita,

(...) que o professor possa ser formado apenas refletindo sobre a sua ação; acreditar neste discurso e apoiá-lo é decretar o fim de nossa profissão, é aceitar que nos tornamos cada vez mais dispensáveis diante do aparato tecnológico que hoje possuímos para transmissão de informação. Também não acreditamos que a formação inicial do professor possa se dar em serviço, não vemos nenhum outro profissional ser formado assim. Por que 
nós deveríamos admitir que para ser professor qualquer tipo de formação possa ser feita? Por isso, reafirmamos que a formação de professores não pode se eximir de uma bagagem filosófica, histórica, social e política, além de uma sólida formação didático-metodológica, visando formar um profissional capaz de teorizar sobre as relações entre educação e sociedade e, aí sim, como parte dessa análise teórica, refletir sobre a sua prática, propor mudanças significativas na educação e contribuir para que os alunos tenham acesso à cultura resultante do processo de acumulação sócio-histórica pelo qual a humanidade tem passado.

O trabalho dentro do curso de pedagogia através das disciplinas já mencionadas foi pautado nessas premissas, uma vez que ensinar "é um ato criador, um ato crítico e não mecânico" (Freire, 1992: 81), por isso, a importância de ir a campo e fazer um trabalho junto à comunidade mostrando que é possível pensar a educação de maneira diferente do que está posto e proposto.

\section{Metodologia}

A metodologia utilizada nas atividades das disciplinas de Estágio Supervisionado I, II, III e Psicomotricidade, Brincadeiras e Jogos na Educação teve como orientação teórica o materialismo-histórico-dialético, e as leituras das obras de Paulo Freire e o método utilizado foi o qualitativo-quantitativo.

O método, como pontua Barbosa (2005),

[...] não é só ponto de partida ou a forma a priori de ordenar os passos a serem seguidos no processo de investigação. Admite-se que o método, enquanto resultado de teorização e da atividade efetivadora e teorizada, portanto, enquanto manifestação 
da práxis. [...] é constituinte e se constitui na e pela pesquisa, daí porque ser fundamental o estudo de suas possibilidades (p. 2)

Ademais, o método está intrinsecamente vinculado à realidade hodierna, mas não a uma realidade pronta, acabada, com verdades definidas. De fato, ele "abarca caminho e não apenas uma reta, uma ordenação de passos. Ele indica o olhar político, porém cada um escolhe em que lado político vai ficar" (Barbosa, 2005: 3). Não constitui apenas um conjunto de regras, mas é reconstruído num contexto em que se encontram inseridos os objetos, neste viés que Freire (1992, p. 91) alerta: “... não é possível entender a história sem as classes sociais, sem seus interesses em choque".

A realidade concreta para o método histórico-dialético é uma realidade contraditória, permeada de conflitos e forças antagônicas, em que os fenômenos se compõem de tal forma que nem sempre a realidade percebida e sentida é vista desta forma. Por isso, é preciso refazer esse movimento, desvelar a realidade que o objeto apresenta e retirar o olhar instintivo, cheio de vícios e tendencioso.

Neste sentido, as disciplinas de Estágio foram desenvolvidas junto às Creches Filantrópicas da cidade de Mineiros-GO e nas escolas da Rede Municipal de Ensino, nas quais foi trabalhada no Estágio I (Gestão Escolar) a formação continuada com o grupo gestor, sobre o papel do coordenador dentro das creches; no Estágio II (Educação Infantil), uma oficina sobre "O Desenvolvimento da Atenção e da Volição nas brincadeiras"; e no Estágio III (Ensino Fundamental) a relação teoria e prática em sala de aula e desenvolvimento de projetos.

Na disciplina de Psicomotricidade, Brincadeiras e Jogos na Educação foi desenvolvido um projeto chamado Rua do Lazer Tarde da Pipa, em que as crianças da comunidade, junto de seus familiares, são convidadas a participar das brincadeiras que outrora seus pais brincavam na rua. 


\section{Resultados e discussão}

O trabalho teve início com a turma de Estágio I (Gestão escolar) em que os educandos leram o livro Educação da Cidade (2000) tendo como objetivo compreender a percepção de como todos os membros da escola são agentes políticos. A fim de colocar em prática a relação dialógica freireana, montamos um cronograma de formação continuada para os gestores das cinco creches filantrópicas, nas quais foram atendidos 42 profissionais, entre eles professores, coordenadores e diretores, visando discutir o papel do coordenador pedagógico que também é um gestor.

Durante todo o processo de preparação da formação com os coordenadores, os estagiários puderam refletir o quanto ainda estamos no campo do discurso, em que a teoria e a prática se encontram dicotomizadas.

Freire (2000, p. 28) nos lembra da "[...] imperiosa necessidade que temos, educadoras e educadores progressistas, de ser coerentes, de diminuir a distância entre o que dizemos e o que fazemos”, sair do campo do [...] verbalismo ou intelectualismo ou negar a teoria em nome da prática que, assim se arrisca a perder-se em torno de si mesma" (p.29).

Quando o coordenador assume a postura de que ele detém o conhecimento e que há apenas um caminho a ser traçado, ele deixa de cumprir o seu papel que é de articulador e interlocutor, que tem consciência de que é um ser inacabado, suscetível ao erro e à imperfeição. Além do mais, a função do coordenador é socializar o saber docente, estimular a troca de experiências entre os professores, discutir e sistematizar as práticas pedagógicas. Para Freire (1995b, p. 57) "Só na humildade me abro à convivência em que ajudo e sou ajudado".

A partir desta perspectiva, os educandos puderam ousar e propor uma formação fundamentada no diálogo, em que se aprende 
a ouvir para ser ouvido e a detectar o momento certo de intervir quando for necessário.

Freire (1987, p.16) nos lembra que

(...) O diálogo não é um produto histórico, é a própria historicização. É ele, pois, o movimento constitutivo da consciência que, abrindo-se para a infinitude, vence intencionalmente as fronteiras da finitude e, incessantemente, busca reencontrar-se além de si mesma.

A formação continuada possibilitou aos educandos do curso de pedagogia e aos profissionais dessas creches o entendimento de que a aprendizagem pautada no verbalismo excessivo e no silêncio são grandes impeditivos para se estabelecer uma relação dialógica, porque é na palavra que os homens se fazem, ou seja, na ação-reflexão, e "[...] fora da busca, fora da práxis, os homens não podem ser." (Freire, 1987.p. 66).

Outra formação que foi desenvolvida junto aos profissionais das Creches Filantrópicas, e cujo tema nasceu dentro desta relação dialógica em que a disciplina de Estágio se propôs a trabalhar foi "O Desenvolvimento da Atenção e da Volição através das Brincadeiras com Crianças de Zero a Cinco Anos".

O motivo de trabalhar com o tema citado, era uma preocupação entre as educadoras, devido à agitação, a falta de atenção e concentração das crianças na hora das brincadeiras. No diálogo entre estagiários do Curso de Pedagogia, educadoras e o grupo gestor das creches, ficava cada vez mais evidente na fala destes profissionais, que as crianças tinham Transtorno de Déficit de Atenção e Hiperatividade (TDAH) e necessitavam de um remédio para controlar esta disfunção.

O TDAH tem sido muito discutido entre os especialistas. Questiona-se se esta falta de atenção e hiperatividade são uma 
disfunção orgânica ou não. Por isso, temos visto crescer o número de crianças em fase escolar, que são diagnosticadas com TDAH, de maneira aligeirada, por profissionais e que necessitam do uso de psicoestimulantes a base de metilfenidato "[substância de que é feita a Ritalina]", que ajudam as crianças a se concentrarem e evitar a hiperatividade. (Arce, p.105).

Segundo Eidt e Tuleski (2007: 222)

devido à falta de clareza do que seja este quadro clínico e sua frente a outros quadros com sintomas semelhantes, não existindo também estudos consistentes acerca das futuras consequências do uso da medicação.

É interessante salientar que para a Psicologia Histórico-cultural o desenvolvimento das funções superiores, principalmente a atenção (intrapsicológico) só se completam na adolescência, por isso a importância de se ter cuidado com o uso excessivo de medicação.

Foi a partir destas premissas, que iniciamos a discussão com os educadores das creches, para o perigo de diagnósticos precoces, que acabam fomentando o crescimento das indústrias farmacêuticas e mascarando "a crise estrutural da sociedade capitalista" (Eidt \& Ferracioli, 2010, p. 120).

No Estágio III (Ensino Fundamental), os estagiários tiveram contato com a relação teoria e prática discutindo as obras: Pedagogia do Oprimido (1987), Pedagogia da Autonomia (1996) e Pedagogia da Esperança (1992). Após a discussão das mesmas, eles foram estagiar nas escolas da Rede Municipal de Ensino, durante o dia, com crianças de seis a onze anos, e à noite com Jovens e Adultos em salas multisseriadas.

Em campo os estagiários puderam entender que a questão da práxis na educação é de fundamental importância e que as instituições de Ensino Fundamental da cidade de Mineiros-GO, adotam 
a educação do silêncio, uma educação passiva na qual um só fala e outro ouve, contribuindo para uma consciência ingênua; e as discussões que fortuitamente ocorrem no espaço escolar, mais especificamente na sala de aula, acabam ficando no campo do senso comum.

Dificilmente os educadores promovem roda de conversa no ensino fundamental ou partem dos conhecimentos que os alunos trazem de casa. Tudo é proposto e imposto aos educandos, como se eles fossem meros recipientes vazios prontos a serem preenchidos, a sua curiosidade não é levada em conta, ao contrário é uma escola que promove a acomodação e não a inquietação do educando.

Paulo Freire (2001), em sua obra Educação como prática da liberdade já alertava os educadores sobre os perigos de uma educação que não prioriza o diálogo, o debate, a análise da realidade. Para ele a educação "[...] é um ato de amor, por isso, um ato de coragem" (2001, p.104), necessário para se conseguir dirimir todas as mazelas que a educação vem enfrentando. Foi um desafio muito grande para as alunas, através de projetos como Brincadeiras de faz-de-conta, Projeto Literário, Horta Suspensa, realizados nas aulas de regência, conseguir romper o silêncio imposto nas salas de aula pelos educadores aos educandos.

Além do que, muitos professores têm sido formados dentro da concepção neoliberal, e atualmente muitas Secretarias Municipais de Educação coadunam com a mesma política imposta pelo Banco Mundial, propondo formações continuadas nas quais os educadores acreditam que eles são os protagonistas do processo ensino-aprendizagem. Mas estas formações, ao contrário, acabam reforçando o individualismo e uma desintelectuação dos profissionais da educação.

Quando surgem as contradições nas formações continuadas, estas são tratadas como conflitos ou naturalizadas, ou seja, não precisa buscar a origem, a raiz dos problemas, basta apenas um bom "kit" 
pedagógico ou um "fluxo" (roteiro de atividades a serem ministradas em sala de aula pelos educadores) e tudo será resolvido.

Sobre o kit, Arce (2001, p. 278) ressalta que:

Temos a nossa frente um kit desastroso constituído pelo neoliberalismo e que vem travestido de modernidade e progresso, através do aprender a aprender e que está sendo vendido para o professor com a garantia de que, comprando, ele ganhará grátis um novo estatuto profissional e mais liberdade para seu trabalho, ao ser considerado como capaz de refletir sobre sua prática e a partir dela produzir conhecimentos. Resistir a este kit é nosso dever moral e profissional, cabe aos intelectuais denunciarem as consequências nefastas para a educação que o neoliberalismo e seu discurso têm trazido, auxiliando a classe dos professores a não se tornar escrava dentro de seu próprio ambiente de trabalho: a escola.

Para os graduandos em Pedagogia, a realização deste trabalho em sala de aula, foi perceber que:

Não há ensino sem pesquisa e pesquisa sem ensino. Esses que-fazeres se encontram um no corpo do outro. Enquanto ensino continuo buscando, procurando. Ensino porque busco, porque indago e me indago. Pesquiso para conhecer o que ainda não conheço e comunicar ou anunciar a novidade. (Freire, 1996, p. 32)

Na disciplina de Psicomotricidade, Brincadeiras e Jogos na Educação, o resultado da leitura das obras de Paulo Freire, deu origem à Rua do Lazer - Tarde da Pipa, projeto este, que atualmente é de extensão e tem produzido muitos trabalhos de conclusão de curso. O projeto acontece duas vezes ao ano e tem recebido um respaldo muito grande da comunidade local e dos empresários. 
O objetivo do projeto é resgatar, e ao mesmo tempo mostrar aos educandos que não é só brincar por brincar, jogar por jogar. Enquanto brinca, joga, a criança desenvolve a cooperação, atenção, socialização, imaginação, motricidade, raciocínio, memória, habilidades motoras, responsabilidade, respeito mútuo, individual, bem como o espírito de coletividade.

Convêm ressaltar que as brincadeiras são tão importantes na vida da criança quanto dormir e alimentar-se. Nelas, a criança estabelece relações sociais, produz cultura, modifica o contexto, inventa, imagina e cria regras que contribuirão para a construção de sua identidade. Conforme Vigotski (1998), as crianças brincam para compreender o mundo em que vivem.

Esse brincar na infância é muito importante porque ajuda as crianças a resolver os conflitos, ampliar suas relações, colocarem-se no lugar do outro, tomar atitudes diante dos acontecimentos, serem autônomas.

Por isso, esta interação com a comunidade local através do projeto de extensão, nos fez refletir:

Nas sociedades massificadas os indivíduos "pensam" e agem de acordo com as prescrições que recebem diariamente dos chamados meios de comunicação. Nestas sociedades, em que tudo ou quase tudo é pré-fabricado e o comportamento é quase automatizado, os indivíduos "se perdem" porque não têm de "arriscar-se". Não têm de pensar em torno das coisas mais insignificantes; há sempre um manual que diz o que deve ser feito [...]" (Freire, 1981, p. 83)

A Rua do Lazer - Tarde da Pipa, como ação cultural, contribui para que as pessoas se sintam parte desta sociedade e exerçam o seu papel de cidadãos, resgatem suas tradições, brinquem com seus filhos, dialoguem com as pessoas que ali estarão, inclusive oportunizando as crianças a brincar com seus pais e conhecer as 
brincadeiras que outrora brincavam. Aprendem a cuidar desta rua conservando-a limpa.

Destarte, os estudos de Freire também foram levados para o Colégio Estadual Deputado José Alves de Assis, onde atuo como coordenadora pedagógica. Atualmente a escola possui 1265 alunos, sendo 434 no período matutino, 491 no vespertino e 340 no noturno. A escola no período noturno, vinha desde 2013 enfrentando um alto índice de abandono escolar (cerca de 40\%) por parte dos educandos.

Ao adotar a concepção de educação freireana na elaboração do Projeto Político Pedagógico, a escola buscou um diálogo com estes jovens trabalhadores no intuito de saber quais eram as principais causas da evasão escolar.

Estes jovens deixaram claro que muitos se sentiam constrangido em chegar atrasados para assistir as aulas, e a falta de interesse por parte dos professores em relação às suas angústias, os levavam à abandonar a escola antes do final do primeiro semestre.

Segundo Freire (1996, p.135) escutar "[...] significa a disponibilidade permanente por parte do sujeito que escuta para a abertura à fala do outro, às diferenças do outro". Foi exatamente o que a coordenação trabalhou com estes educandos, a escuta das suas dificuldades, o motivo de não virem à escola e a importância de estarem no ambiente escolar.

Esta escuta não significou em concordar e aceitar todas as justificativas dos educandos, e sim fazê-los compreender que só estando na escola é que poderiam em parte resolver uma série de problemas que estão enfrentando como, por exemplo, a falta de tempo para estudar. Desta forma a escola conseguiu reduzir em $20 \%$ o índice de evasão no ensino noturno.

Acreditamos que os outros $20 \%$ estão relacionados ao ambiente escolar que precisa ser atrativo, fazer com que o educando vá para sala de aula desejoso de novas experiências e desejoso de permanecer neste ambiente escolar. 
Os educadores necessitam modificar as suas práticas pedagógicas, trabalhar aulas que façam sentido na vida do educando, que preparem para a dimensão do mundo do trabalho, que ajudem a serem criativos, conscientes de seu papel na sociedade, solidários, e não mão de obra barata a serviço do capital. Este é um dos "Calcanhares de Aquiles" do Ensino Noturno.

\section{Considerações finais}

A nossa intenção não é finalizar nada, pelo contrário, as leituras propostas apenas nos possibilitaram, na medida do possível, fazer uma educação fundamentada no princípio da dialogicidade; e que ensinar exige a convicção de que a mudança é possível, quando existe respeito à autonomia do educando.

Ademais, o curso de pedagogia precisa reverter esta lógica da produção, pautada nos princípios do neoliberalismo, e criar mais espaços de reflexão, entendendo que "ensinar não é transferir conhecimento, mas criar possibilidades para a sua própria produção" (Freire, 1996, p. 52), respeitando os saberes dos educandos.

Sabemos que não é fácil trabalhar dentro da perspectiva freireana e lutar contra os empecilhos que nos são impostos pelas políticas educacionais coadunadas com as políticas internacionais. Temos, às vezes, a impressão de que remamos contra a maré, quando nos deparamos com inúmeras produções científicas brasileiras que trazem termos como formação permanente, prática reflexiva, desenvolvimento de competências, histórias de vida, interações sociais, reflexão na e sobre a prática.

Estes termos aparecem em artigos, ensaios, relatos de experiência, periódicos e outros, como se a salvação da educação estivesse sedimentada neste novo discurso neoliberal. 
Ademais, nem todos os educadores que são formadores têm o discernimento e o rigor teórico para lidar com essa enxurrada de novas terminologias e acabam caindo num ecletismo que, ao invés de contribuir com a educação de nossos educandos, cria mais problemas devido às contradições e ideologias subjacentes nas teorias, ou seja, o educador reforça uma "educação bancária".

Segundo Freire (1987, p. 60)

Na medida em que esta visão "bancária" anula o poder criador dos educandos ou o minimiza, estimulando sua ingenuidade e não sua criticidade, satisfaz aos interesses dos opressores: para estes, o fundamental não é o desnudamento do mundo, a sua transformação.

$\mathrm{Na}$ realidade essa transformação retratada por Freire não se trata de um humanismo. Tal transformação não passa de um humanitarismo, para a manutenção do status quo, em que o educando e educador são presas fáceis deste discurso, tornando-se alheios a tudo e permanecendo-se com uma consciência ingênua.

Neste sentido, podemos entender que estas evidências confirmadas neste relato de experiência que fizemos não podem ser consideradas verdades estáticas, porque toda realidade, de qualquer natureza, sempre está em movimento, porquanto são verdades parciais, e não definitivas.

\section{Referências bibliográficas}

Arce, A. (2001). Compre o kit neoliberal para Educação Infantil e ganhe grátis os dez passos para se tornar um professor reflexivo. Educ. Soc., 22(74), 251-283).

Eidt, N. M. \& Ferracioli, M. U. (2010). O Ensino Escolar e o Desenvolvimento da Atenção e da Vontade. Superando a concepção organicista do Transtorno de Déficit de Atenção e Hiperatividade (TDAH). In A. Arce (org.), Quem tem medo de ensinar na educação infantil? Em defesa do ato de ensinar (pp. 93-121). Campinas, SP: Editora Alínea. 
Arruda, M. (1998). ONGs e o Banco Mundial é possível colaborar criticamente? In L. Tommasi, M. J. Warde, \& S. Haddad (org.), O Banco Mundial e as politicas educacionais (2. ${ }^{a}$ Ed.) São Paulo: Cortez.

Barbosa, I. G. (2005). Método: em busca de uma definição. (FE/UFG, mimeografado).

Eidt, N. M. \& Tuleski, S. C. (2007). Discutindo a Medicalização Brutal em uma Sociedade Hiperativa. In M. G. D., Facci \& M. Meira. (org.), Psicologia histórico-cultural: contribuições para o encontró entre a subjetividade e a educação. São Paulo: Casa do Psicólogo.

Freire, P. (1979). Conscientização: teoria e prática da libertação: uma introdução ao pensamento de Paulo Freire / Paulo Freire (Trad. Kátia de Mello e Silva; revisão técnica de Benedito Eliseu Leite Cintra). São Paulo: Cortez \& Moraes.

Freire, P. (1981). Ação Cultural para a Liberdade e outros escritos (5. ${ }^{a}$ ed). Rio de Janeiro: Paz e Terra.

Freire, P.(1987). Pedagogia do oprimido (3. ${ }^{a}$ ed.) Rio de Janeiro: Paz e Terra.

Freire, P. (1991). A importância do ato de ler (26. ${ }^{a}$ ed.) São Paulo: Cortez, (Coleção polêmica do nosso tempo).

Freire, P. (1992). Pedagogia da esperança: um reencontro com a pedagogia do oprimido. Rio de Janeiro: Paz e Terra.

Freire, P. (1995a). Professora sim, tia não: cartas a quem ousa ensinar (6. ${ }^{a}$ ed.). São Paulo: Olho d'água.

Freire, P. (1995b). À sombra desta mangueira. São Paulo: Olho d'água.

Freire, P. (1996). Pedagogia da Autonomia. Rio de Janeiro: Paz e Terra.

Freire, P. \& Shor, I. (1997). Medo e ousadia: o cotidiano do professor (7. ${ }^{a}$ ed.). Rio de Janeiro: Paz e Terra.

Freire, P. (2000). A educação na cidade. São Paulo: Cortez.

Freire, P. (2000). Pedagogia da indignação - cartas pedagógicas e outros escritos. São Paulo: UNESP.

Freire, P. (2001). Educação como prática da liberdade (25. ${ }^{\mathrm{a}}$ ed.). Rio de Janeiro: Paz e Terra.

Leher, R. (1998). Da ideologia do desenvolvimento à ideologia da globalização: a educação como estratégia do Banco Mundial. Tese de Doutorado (não publicada). São Paulo: Faculdade de Educação da Universidade de São Paulo.

Shah, I. (1999). O falcão. In D. Ristof (org.), Universidade em foco: reflexões sobre educação superior (p. 220). São Paulo: Insular.

Vázquez, A. S. (1977). Filosofia da práxis (Trad. Luiz Fernando Cardoso, 3. ${ }^{a}$ ed.). Rio de Janeiro: Paz e Terra.

Vigotski, L. S. (1998). A formação social da mente: o desenvolvimento dos processos psicológicos superiores. (Trad. José Cipola Neto, Luis Silveira Menna Barreto e Solange Castro Afeche, $6{ }^{a}$ ed.). São Paulo/SP: Martins Fontes. 